\title{
Onde estão as mulheres nessa história? Uma oficina sobre representatividade feminina nas ciências.
}

\author{
Maria Alice N. Silva ${ }^{1}$, Thalia S. Santana ${ }^{1}$, Letícia S. Camargo ${ }^{1}$, Natália C. \\ Louzada $^{1}$, Ramayane B. Braga ${ }^{1}$, Adriano H. Braga ${ }^{1}$ \\ ${ }^{1}$ Instituto Federal Goiano - Campus Ceres (IF GOIANO) \\ Caixa Postal 51 - 76.300-000 - Ceres - GO - Brasil \\ \{mariaalicenunessilva, thaliassantana15, letycamargo15\}@gmail.com, \\ \{natalia.louzada, ramayane.santos, adriano.braga\}@ifgoiano.edu.br
}

\begin{abstract}
The present work is an educational activity report of conducting a timeline construction workshop, about women in the history of science. The aim of the workshop is to retell the story with the participation of women, and thus bring representativeness to areas that are often considered to be masculine. For the development of this activity, eight women from the three major areas of science were surveyed: human, exact and biological. Along 1 h30 minutes, it counted on the participation of students from a technical, in favor of the identification and acknowledgment of female figures obliterated in historiography.
\end{abstract}

Resumo. $O$ presente trabalho constitui um relato de experiência pedagógica, de oficina de construção de linha do tempo de mulheres na história da Ciência. O objetivo da oficina é recontar a história com a participação feminina, e dessa forma trazer representatividade para áreas tidas muitas vezes como masculinas. Para o desenvolvimento dessa atividade foram pesquisadas oito mulheres das três grandes áreas das ciências: humanas, exatas e biológicas. Com duração de 1 h30 minutos, a ação contou com a participação de alunos do ensino médio técnico, em prol da identificação e re(conhecimento) de figuras femininas obliteradas na historiografia.

\section{Introdução}

O desequilíbrio de gênero na produção científica mundial é notório. Confirme a UNESCO (2020), apenas $28 \%$ dos atuais pesquisadores são mulheres, o que se agrava no caso das ciências exatas, tradicionalmente representadas no imaginário social como áreas "masculinas" (MAIA, 2016). A referida desigualdade se deve tanto à histórica restrição profissional imposta às mulheres, quanto ao apagamento de sua contribuição no âmbito das narrativas dedicadas à história das ciências.

Nesse sentido, projeto de extensão Meninas Digitais no Cerrado foi convidado pelo IF Goiano - Campus Ceres para promover uma oficina, abordando tal problemática, durante evento acerca do Dia Internacional da Mulher. Considerando os anais do Women in Information Technology (WIT) entre os anos de 2017 a 2019, diversos trabalhos relatam a realização de oficinas como estratégia para ampliação da participação feminina, a exemplo de Júnior et al. (2019), Amim et al. (2019), Soares et al. (2018) e Salgado et al. (2017). Entretanto, a maioria destes refere-se ao ensino de programação e à questões profissionais e de gênero, não tendo sido encontrados relatos 
de experiência de ações voltadas ao re(conhecimento) e ressignificação de figuras femininas de êxito nas diversas áreas das ciências.

Desta forma, a atividade cujo desenvolvimento é aqui relatado constitui uma releitura de outra oficina ministrada anteriormente pelo projeto que, por sua vez, continha a proposta de criar uma linha do tempo com importantes mulheres da história da computação. Esta segunda proposição, todavia, não limitou-se ao recorte historiográfico da informática, abrangendo as três grandes áreas de conhecimento: ciências biológicas, exatas e humanas. Tal escolha foi feita tendo em vista a diversidade do público-alvo da atividade, composto por estudantes dos cursos técnicos em Agropecuária, Meio Ambiente e Informática para Internet, ofertados de forma integrada ao ensino médio na referida instituição de ensino.

Assim, o presente trabalho tem como objetivo apresentar o relato de experiência da oficina intitulada "Onde estão as mulheres nessa história?", descrevendo todas as etapas de realização desta atividade. Este estudo está subdividido da seguinte forma: a Seção 2 compreende o relato de experiência do planejamento e execução da oficina; a Seção 3 os resultados e discussões; e as Considerações Finais na Seção 4.

\section{Relato de Experiência}

A comissão organizadora da oficina foi formada pelos integrantes do referido projeto de pesquisa e extensão. A programação ocorreu no período vespertino, destinando-se aos alunos do ensino médio técnico, mas não limitando-se a tal devido à pluralidade de cursos da instituição. A atividade contou com a presença de 42 estudantes, sendo este número superior à quantidade limite de vagas oferecida pelo evento (40). Acredita-se que isto tenha ocorrido pela consolidação do projeto como um coletivo referência, bem como pela própria indagação gerada pelo título da atividade.

Durante o planejamento da oficina, a parte mais significativa foi a definição de perfis femininos importantes para as distintas áreas de conhecimento, abordando tanto pioneiras quanto mulheres em auge na atualidade. A seleção foi feita com base em bibliografia específica, a exemplo de Favilli (2017), e em reportagens jornalísticas recentes. A escolha também foi pautada pela diversidade etnocultural, apresentando mulheres negras, asiáticas, latinas, brasileiras, dentre outras. Ao todo, oito figuras femininas foram selecionadas por área, totalizando 24 mulheres, conforme o Quadro 1.

Quadro 1. Lista de mulheres por área em ordem cronológica. Fonte: Própria (2020).

\begin{tabular}{|l|l|l|}
\hline Exatas & Humanas & Biológicas \\
\hline Wang Zhenyi (1768) & Jane Austen (1775) & Florence Nightingale (1820) \\
\hline Ada Lovelace (1815) & Nísia Floresta (1810) & Alice Ball (1892) \\
\hline Marie Curie (1867) & Cora Coralina (1889) & Bertha Lutz (1894) \\
\hline Lise Meitner (1878) & Gabriela Mistral (1889) & Barbara McClintock (1902) \\
\hline Hedy Lamar (1914) & Hannah Arendt (1906) & Nise da Silveira (1905) \\
\hline Katherine Johnson (1918) & Frida Kahlo (1907) & Dorothy Hodgkin (1910) \\
\hline Joana Döbereiner (1924) & Simone de Beauvoir (1908) & Rosalind Franklin (1920) \\
\hline Katie Bouman (1989) & Angela Davis (1944) & Ester Sabino, Jaqueline Goes (2020) \\
\hline
\end{tabular}


Foram confeccionados um par de cartões para cada uma das mulheres, sendo um destes com fotos das mesmas e seus nomes, e o outro com imagens representativas de seus respectivos feitos pelos quais são mais conhecidas. $O$ recorte temporal se estendeu entre os anos de 1750 até o período atual. As personagens foram agrupadas por cores, de acordo com a área de conhecimento. Ademais, também foi construído um painel com a linha do tempo onde seriam pregados os cartões. E, finalmente, elaborou-se um questionário para aplicação ao término da atividade.

A oficina foi dividida em quatro etapas, considerando o tempo disponibilizado pela organização do evento: cerca de 1 h30 minutos. Nesse sentido, a subdivisão da atividade foi feita da seguinte maneira: I. Sensibilização, II. Experimentação, III. Discussão e IV. Avaliação, detalhadas a seguir.

A sensibilização (20 minutos) corresponde ao tempo inicial em que a proposta da oficina é exposta aos presentes. A atividade iniciou-se com a fala das coordenadoras, que recepcionaram os alunos e apresentaram o projeto, além de instigar a discussão sobre estereótipos de gênero que integram o imaginário social. Por conseguinte, discutiu-se a natureza relativa da História, que não possui uma versão única dos fatos, visto que o método historiográfico é perpassado pela subjetividade dos sujeitos, os quais, distintos que são, constroem narrativas diferentes para narrar um mesmo fato.

$\mathrm{Na}$ fase de experimentação (10 minutos), os participantes foram convidados a remontar a linha do tempo associando três variáveis: uma personagem mulher; uma realização científica e um determinado período histórico. Os estudantes foram informados que, em conjunto, deveriam verificar a figura feminina e sua contribuição, encaixando-nas ao momento histórico de seu nascimento - sem o auxílio da internet.

A discussão (40 minutos) ocorreu logo após os alunos terminarem de organizar a linha do tempo. E, como esperado, ela não estava completamente correta, de modo que as integrantes do projeto reposicionaram os pares de cartões, apresentando brevemente as histórias de cada uma das mulheres. À medida em que "corrigiam" a atividade, as integrantes também problematizavam os motivos para a obliteração frequente destas personagens. Trabalhou-se nesta etapa uma investigação à contrapelo da narrativa historiográfica, buscando levantar as camadas de discursos androcêntricos que, sobrepostas na arqueologia da história das ciências, soterraram mulheres e a relevância histórica de suas contribuições.

Por último, na etapa de avaliação (20 minutos), após o fim da atividade, os alunos foram convidados, de forma voluntária, a preencher um questionário avaliativo. O formulário foi aplicado em vias impressas, contendo 12 questões objetivas e um campo para dúvidas e comentários. Os dados foram tabulados em planilhas eletrônicas utilizando a plataforma Google Planilhas.

\section{Resultados e Discussão}

Todos os participantes presentes se dispuseram a preencher o formulário avaliativo. O público foi composto por 28 meninas (66,7\%), 11 meninos $(26,2 \%)$ e três pessoas que não quiseram se identificar em termos de gênero $(7,1 \%)$. Quando questionados acerca da área em que possuem maior afinidade, houve certa homogeneidade entre as três grandes áreas: $35,7 \%$ das respostas indicaram as ciências 
exatas; 33,3\% ciências humanas; e 31\% ciências da saúde. Analisando somente as meninas, a maioria afirmou se identificar mais com as ciências exatas (39,3\%). Já os homens corresponderam, empatados, à 36,4\% para ciências humanas e ciências exatas.

Quanto aos discentes de uma forma geral, identificou-se que a maioria pretende optar profissionalmente pela área de ciências biológicas (ciências da saúde) - 40,5\%. Esta área foi seguida pelas ciências humanas $(31 \%)$ e, por último, estiveram ciências exatas $(26,2 \%)$ - além de $2,4 \%$ que não souberam responder.

Assim sendo, tanto entre meninas quanto entre meninos, as respostas ao questionário indicaram uma incongruência importante. Isso porque, embora 39,3\% das mulheres questionadas se afinize mais com as ciências exatas, $40 \%$ delas disse que optará profissionalmente por formações ligadas às ciências biológicas. $\mathrm{O}$ mesmo ocorre com os homens, dentre os quais há maior afinidade por exatas e humanas $(36,4 \%)$ (e somente $27,3 \%$ por biológicas), embora $36,4 \%$ deles pretendam cursar graduações na área de ciências biológicas.

Ao serem questionados se os cursos superiores que farão são efetivamente os cursos que gostariam de cursar, $85,7 \%$ dos estudantes responderam positivamente. Os demais ainda não sabem, ou citaram desejo por cursos de "menor reconhecimento" que serão preteridos na escolha profissional, face a uma formação vista como de "melhor retorno financeiro". Outro caso refere-se aos que desejam cursar formações de grande reconhecimento social (a exemplo de Medicina) e que, todavia, afirmaram pretender cursar formações diferentes daquela desejada, embora também na área da saúde. Os três principais motivos mais elencados para escolha do curso entre os estudantes conforme as respostas são: vocação (59,5\%); mercado de trabalho (16,7\%); e família (14,3\%).

Considerando as figuras femininas apresentadas, 38 (90,5\%) dos indivíduos analisados, responderam conhecer menos de $50 \%$ das mulheres e somente quatro $(9,5 \%)$ possuíam conhecimento de cerca de $50 \%$ das personagens. Não houve respostas de participantes indicando conhecer mais de $50 \%$ das personagens femininas trabalhadas, o que reforça o cenário de apagamento feminino.

Com relação às áreas de conhecimento, os estudantes tiveram maior facilidade em distinguir mulheres das ciências humanas $(45,2 \%)$, seguidas de ciências exatas $(38,1 \%)$ e ciências biológicas $(16,7 \%)$. Contudo, $41,2 \%$ das participantes do sexo feminino disse se identificar pessoalmente com as ciências exatas e ciências humanas, $o$ que desassocia conhecimento acerca da representatividade feminina numa determinada área e identificação pessoal com a mesma.

Por fim, ao avaliar a oficina, 97,2\% dos alunos afirmaram estarem satisfeitos ou muito satisfeitos com a oficina, além de que, mais de $90 \%$ consideraram fortemente recomendável a participação na mesma para outros colegas.

\section{Considerações Finais}

Este artigo relata o desenvolvimento de uma oficina sobre representatividade feminina nas três grandes áreas das ciências; biológicas, exatas e humanas, bem como a importância desses referenciais femininos na formação acadêmica de estudantes do ensino médio técnico, além de inspirá-las a seguir carreiras que antes não acreditassem ser possível. Outrossim, a realização dessa oficina em uma data dedicada a luta das 
mulheres por direitos iguais reforça a necessidade de se utilizar a história como ferramenta de desconstrução de preconceitos.

Os dados obtidos como resultado da ação nos mostram uma incongruência entre afinidade pessoal, representatividade feminina e opção profissional; haja vista que, no caso das meninas participantes, embora a maioria se identifique pessoalmente com as ciências exatas, a maior parte das participantes reconheceu com mais facilidade as figuras femininas partícipes da história das ciências humanas, e disse pretender optar por carreiras na área de ciências biológicas.

Acredita-se que, conforme Cunha et al. (2014), tendências por escolhas profissionais elitizadas e por profissões historicamente ligadas ao cuidado são reflexos de processos de educação e de socialização anteriores, os quais estimulam mulheres para campos de saúde, educação e bem-estar. Todavia. em trabalhos futuros, objetiva-se expandir a aplicação e o público-alvo desta oficina visando melhor compreensão da relação entre afinidade, representatividade e escolha profissional entre jovens mulheres.

\section{Referências}

Amim, F., Moura, J., Fernandes, K., Vargas, K., \& Mello, A. (2019). Oficina Gurias na Computação: três horas de imersão feminina na área da Computação discutidas em detalhes. In Anais do XIII Women in Information Technology, (pp. 149-153). Porto Alegre: SBC. doi:10.5753/wit.2019.6727.

Cunha, M. B., Peres, O. M. R., Giordan, M., Bertoldo, R. R., Quadros Marques, G., \& Duncke, A. C. (2014). As mulheres na ciência: o interesse das estudantes brasileiras pela carreira científica. Educación química, 25(4), 407-417.

Favilli, E. Histórias de Ninar para Garotas Rebeldes. São Paulo: Vergara \& Riba Editoras, 2017.

Júnior, W., Santos, L., Manzano, A., Farias, Â., Souza, T., Badji, I., Prietch, S., \& Resmini, R. (2019). Techno Girls: oficinas de programação de jogos para estudantes de escolas públicas. In Anais do XIII Women in Information Technology, (pp. 11-20). Porto Alegre: SBC. doi:10.5753/wit.2019.6708.

Maia, M. M. (2016). Limites de gênero e presença feminina nos cursos superiores brasileiros do campo da computação. Cadernos Pagu, (46), 223-244.

Organização das Nações Unidas para Educação, Ciência e Cultura (UNESCO). 2020. UNESCO Celebra o Dia Internacional das Mulheres e Meninas na Ciência. Disponível em: https://pt.unesco.org/news/unesco-celebra-o-dia-internacional-dasmulheres-e-meninas-na-ciencia. Acesso em: 06/03/2020.

Salgado, L., Cappelli, C., \& Avelino, M. (2017). Oficina de Re(design) da Interação do Whatsapp para alunas da rede municipal de Petrópolis. In Anais do XI Women in Information Technology. Porto Alegre: SBC. doi:10.5753/wit.2017.3399.

Soares, C. N., Leite, L. L., de Araújo, A. P. F., \& Holanda, M. (2018). Mulheres de Ferro: Relato de Prática Utilizando Arduíno com Alunas do Ensino Médio em uma Escola Pública. In Anais do XII Women in Information Technology. Porto Alegre: SBC. doi:10.5753/wit.2018.3383. 